\title{
Accounting Systems in Cultural Context: A Research Framework for China Studies in Global Economy
}

\author{
Anthony Moung Yin Chan \\ Ryerson University, Toronto, Canada
}

\begin{abstract}
The People's Republic of China (PRC) is a country that has great potential to international businesses. Her enormous market, resources, and labor power are important to other countries in this age of global economy. Research studies on the PRC are valuable not only to policymakers in the PRC but also to a larger audience in the global business community. Accounting standards and practices are central to the economic order of any society. As accounting systems are not isolated from social and cultural systems, towards an understanding of social/cultural environments interacting with accounting systems in the PRC in turn facilitates the international investors to interpret financial information and to set strategies in doing businesses in the country. It is expected that the research results of this kind of projects will have implications to different aspects of financial disclosure of companies in the PRC. Being grounded in the current accounting literature, the proposed conceptual framework in this paper is to discern the interconnections between accounting systems and cultural factors in the PRC. It aims at contributing to the accounting body of knowledge and to provide practical insights for global managers.
\end{abstract}

Keywords: accounting and culture, framework for contextual research, China studies

\section{Introduction}

Accounting is always regarded as a discipline to provide financial information for economic decisions. Therefore, the developments of accounting objectives, theories, systems, or practices need to be considered in the light of economic contributions to the social environment. The direct link between accounting systems and economic systems is one of the basic accounting functions: to allocate the fund resources of the society from inefficient economic entities to efficient ones through the financial signals provided by various kinds of accounting reports.

The prior research literature reveals that similar political, cultural, and socioeconomic environments produce similar accounting practices and standards among nations, while different environments produce different systems (e.g., American Accounting Association [AAA], 1977; Choi \& Mueller, 1984; Nobes \& Parker, 1991). Therefore, instead of searching for the best accounting practices that apply universally, the school of accounting thought on cultural aspects of accounting proposes the following research question: within a specific cultural environment, how to construct the components of the accounting systems (e.g., accounting standards) so that the accounting systems (fit the social context) can have maximum contributions to its neighboring social, cultural, and economic systems?

Anthony Moung Yin Chan, Professor of Accounting, Ted Rogers School of Management, Ryerson University. Email: myachan@ryerson.ca. 
To approach this research question having a cultural and sociological nature, a matching methodology informed by such theoretical orientations is appropriate. In other words, qualitative research methods using both deductive and inductive approaches can be utilized. For arguments of matching qualitative research methods to qualitative research questions, two useful references are: Morgan and Smircich (1980) and Burrell and Morgan (1979).

Cultural theories are meta-paradigms and can be served as qualitative research approaches for empirical enquiries. Established cultural theories utilized in accounting studies include symbolic interactionism, German critical theory, French critical theory, structuration theory, etc. (some examples of the accounting studies are Tomkins, 1982; Laughlin, 1987; Hopper, Storey, \& Willmott, 1987; Macintosh \& Scapens, 1989; 1990).

\section{A Pilot Exploration in the Chinese Context}

Towards a theoretical answer to the research question "within a specific cultural environment, how to construct the components of the accounting systems (e.g., accounting standards) so that the accounting systems (fit the social context) can have maximum contributions to its neighboring social, cultural, and economic systems” can be considered a long-term goal for researchers working in this field. The author tried a pilot exploration in the Chinese context to reflect upon the Chinese experience on accounting standard-setting in the light of the needs of international managers and investors.

To apply the research question to the Chinese context, the author made three trips to Shanghai, Sichuan, and Beijing in China to explore the possibilities: (1) to review the different aspects of accounting activities (systems, practices, issues, etc.) in the PRC; (2) to identify the major social and cultural dynamics of the country; and (3) to discern the interconnections between accounting phenomena and cultural factors. Through the trips, the author made contacts with academic institutes, accounting professional bodies, government agencies, and business enterprises in the PRC.

The first trip to Shanghai was to visit the Shanghai University of Finance and Economics (one of the leading accounting universities in China). The main purpose of the trip was to understand the current accounting issues in China and to explore carrying out empirical accounting research in China. It was delightful to find out that academics, regulatory authorities, and accounting practitioners were all cooperative with overseas researchers. They showed much willingness to keep contacts with overseas visitors.

Visited libraries and research centers, some useful literature written in Chinese on accounting issues in China were collected. In return, the author gave a seminar and joined a research forum on "Western Experiences on Accounting Standard Setting” and "Accounting Systems in the Western World”.

The second trip to Sichuan had the main purpose to understand the accounting situation of the inland part of China. It is so common for accounting researchers to choose the more developed cities or those cities more open to the western world located at the eastern part of China (such as Shanghai, Xiamen, Guangzhou, or Shenzhen) when they start studying the accounting systems of China. These cities are undoubtedly important places to visit when accounting researchers study China. However, as they are so developed and special to China, they may not represent the majority situation of the country.

Gone to the inland Sichuan, the author focused on understanding the accounting concerns common to normal practitioners in the inland part of China. Through visits to the leading universities in Sichuan, the author was informed about the current accounting problems in China. 
The third trip to Beijing was to participate in the International Conference on Accounting Theory organized by the People's University which is considered another leading accounting university in China. The conference attracted top accounting professors all around China and overseas delegates. Speeches were made during the conference by high-rank officers of the Ministry of Finance and the Accounting Society of China. By participating in the event, the author gained an important overview of the research trends, methods, and concerns of the top accounting academics in China. In brief, all the three trips served their purposes and are considered useful for this study.

This pilot study includes a literature review of the primary documents written in Chinese. Three areas of data are particularly relevant to this study: literature on the Chinese culture and social systems, on the accounting standard-setting process, and on the contents of the Chinese accounting standards. Journal articles, research reports, conference papers, meeting minutes and discussion papers of the Accounting Society of China Research Group on Accounting Standards, and administrative memos and reports of the Ministry of Finance are all examples of this kind of literature. In the PRC, Accounting Research published by the Accounting Society of China and Finance and Accounting published by the Ministry of Finance are the two most respected journals written in Chinese.

\section{A Conceptual Framework Resulted from the Pilot Exploration}

From about the 1970s, the research approach of "contextual analysis of accounting” has been strongly advocated by many writers in the accounting research community (e.g., Hopwood, 1979; 1987; Laughlin, 1987). There are at least two interrelated viewpoints for such advocacy.

First, as Hopwood (1979, p. 145) has frankly admitted, accounting researchers understand very little "about the actual functioning of accounting systems”. An exploration of the social/cultural context of the systems will in turn enrich our understanding of these systems: "accounting information is only of importance in a given context, and thus that the implications of its context should be considered as an integral part of the understanding of an accounting system” (Puxty, 1979, p. 1). This rationale suggests that a contextual analysis can help explain the reason "why an accounting representation takes a particular precise form" (Gallhofer \& Haslam, 1988, p. 1-9-2).

Second, and more specifically, there has been an increasing awareness in the accounting research community that accounting and managerial systems in practice are not only technical and technological but also social and organizational (Hopwood, 1974). The systems thus "need to be understood by reference to the context in which they are placed which supplies the important meanings for the more tangible elements" (Laughlin, 1987, p. 480). In other words, the investigation of the social and cultural contexts of accounting systems is also an investigation of the social and cultural nature of accounting: "A concern with the social context is important if accountants are to understand their position and roles in society and if the significance of accountancy is to be assessed" (Puxty, Willmott, Cooper, \& Lowe, 1987, p. 273).

In essence, a general appreciation of the importance of contextual analysis for accounting research, according to the contemporary accounting literature, is the recognition of the influences of "context" on “accounting”. Providing some substantive examples, Burchell, Clubb, and Hopwood (1985, pp. 382-385) reviewed some research reports which identified occasions of social changes in the past decades as contextual forces that accounting changes followed: the growth of the public character of accounting information (Gilling, 1976); the increasing recognition of consumer rights (Vogel, 1978); the acknowledgment of significant externalities associated with the conduct of business (Estes, 1976; Ramanathan, 1976). 
The relationship between accounting and context can be considered reciprocal, too. The one-way relationship, implied in the above, suggests that accounting is influenced by contextual forces. However, it is also believed that accounting and context have mutual impacts: "Rather than simply reflecting the context in which it operates, accounting has a power to influence its own context” (Burchell et al., 1985, p. 385). The recognition of accounting consequences to its own context is an "accounting of accounting" (Hopwood, 1985, p. 371). Figure 1 below exhibits the reciprocal relationship between accounting and context.

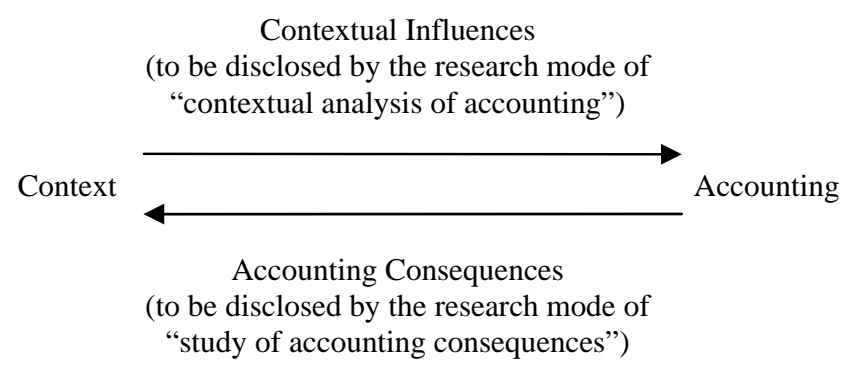

Figure 1. A reciprocal relationship between accounting and context.

Considering this reciprocal relationship between accounting and context and if a set of desirable contextual parameters is determinable, the corresponding accounting systems can be developed by the help of the research results of "contextual analyses of accounting". When the corresponding accounting practices and standards are actually implemented, they are expected to function toward the actualization of the desirable parameters under the forces of "accounting consequences" in the reciprocal relationship. As accounting functions toward the actualization of the set of desirable parameters built upon the will and interest of the general public, accounting becomes “an accountable accounting” (Hopwood, 1985, p. 371).

Figure 2 summarizes this possible contribution of the research mode of "contextual analysis of accounting" through the reciprocal relationship between accounting and context. Desirable Contextual Parameters Designed by Policymakers
Based on the Will of the General Public

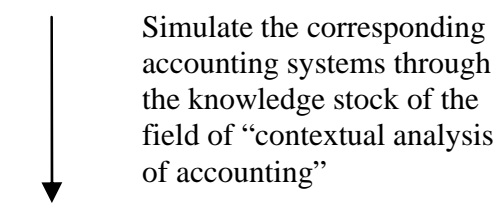

Implement the Estimated Accounting Systems Which Are

Designed to Contribute to the Welfare of the General Public

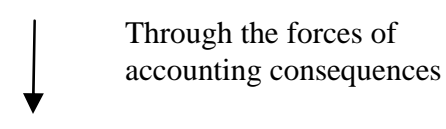

Toward the Actualization of the Desirable Contextual Parameters

Figure 2. Logic to identify a specific value of the research mode of "contextual analysis of accounting" through the reciprocal relationship between accounting and context. 


\section{The Conceptual Framework Applied to China Studies on Accounting Systems in Cultural Context}

To apply the conceptual framework in the last section to China studies, accounting standard-setting can be the first research focus. This area is not only a concerned issue among international managers and investors doing businesses in China but also a hot topic right now among accounting policymakers in the PRC, which means that data availability is better guaranteed. Also, this area is important not only to the future well-being of the Chinese economy but also to international accounting harmonization. In addition, this area is conceptually rich to study and to demonstrate cultural and social systems interacting with accounting systems (as both cultural factors and accounting standard-setting are macro systems).

For many years, accounting practices of enterprises in the PRC are governed by rigid regulations and rules set up by the Ministry of Finance, but not governed by concise accounting standards as in the West. However, along with the recent economic reform towards market economy in the PRC, rigid accounting rules do not work anymore in today's much more diverse Chinese enterprises. As a result, accounting standard-setting became a priority among policymakers in the PRC (C. Liu, Yao, Hu, \& L. Liu, 2011; Luo, Xue, \& Zhang, 2008).

To work on the accounting standard-setting project, the Accounting Society of China (the national association for accountants) set up a research group on accounting standards. The mission of the group is to recommend accounting standards to be approved by policymakers in the government. The group published three influential articles which inspired many later studies in the area. However, accounting standard-setting is still a long-term professional and regulatory endeavor in the PRC.

\section{References}

American Accounting Association [AAA]. (1977). The AAA's morphology for comparative accounting systems. Accounting Review Supplement to Vol. 52, p. 99.

Burchell, S., Clubb, C., \& Hopwood, A. G. (1985). Accounting in its social context: Towards a history of value added in the United Kingdom. Accounting, Organizations and Society, 10(4), 381-413.

Burrell, G., \& Morgan, G. (1979). Sociological paradigms and organizational analysis. London: Heinemann.

Choi, F. D. S., \& Mueller, G. G. (1984). International accounting (pp. 45-52). New Jersey, NJ: Prentice-Hall, Inc..

Estes, W. R. (1976). Corporate social accounting. New York, NY: John Wiley \& Sons.

Gallhofer, S., \& Haslam, J. (1988). The aura of the published accounting report in the context of a crisis situation: Germany and developments of the First World War. Paper presented at the Second Interdisciplinary Perspectives in Accounting Conference, July 11-13, 1988, Manchester, United Kingdom.

Gilling, D. M. (1976). Accounting and social change. International Journal of Accounting, 59-71.

Hopper, T., Storey, J., \& Willmott, H. (1987). Accounting for accounting: Towards the development of a dialectical view. Accounting, Organizations and Society, 12(5), 437-456.

Hopwood, A. G. (1974). Accounting and human behaviour. Haymarket Publishing.

Hopwood, A. G. (1979). Editorial. Accounting, Organizations and Society, 4(3), 145-147.

Hopwood, A. G. (1985). The tale of a committee that never reported: Disagreements on intertwining accounting with the social. Accounting, Organizations and Society, 10(3), 361-377.

Hopwood, A. G. (1987). The archeology of accounting systems. Accounting, Organizations and Society, 12(3), 207-234.

Laughlin, R. C. (1987). Accounting systems in organizational contexts: A case for critical theory. Accounting, Organizations and Society, 12(5), 479-502.

Liu, C., Yao, L., Hu, N., \& Liu, L. (2011). The impact of IFRS on accounting quality in a regulated market: An empirical study of China. Journal of Accounting, Auditing and Finance, 26(4), 659-676.

Luo, T., Xue, J., \& Zhang, H. (2008). Analysis of new accounting standards on the impact of the value relevance of accounting information. China Accounting Review, 129-140. 
Macintosh, N. B., \& Scapens, R. W. (1989). Management control systems: A structuration theory analysis. Paper presented at the International Conference on Management Control Systems jointly organized by the Management Control Association and the Accounting Behaviour and Organizations Section of the American Accounting Association at London Business School, July 10-12, 1989, pp. 1-28.

Macintosh, N. B., \& Scapens, R. W. (1990). Structuration theory in management accounting. Accounting, Organizations and Society, 15(5), 455-477.

Morgan, G., \& Smircich, L. (1980). The case for qualitative research. Academy of Management Review, 5(4), 491-500.

Nobes, C., \& Parker, R. (1991). Comparative international accounting (pp. 47-50). U.K.: Prentice Hall International (U.K.) Ltd..

Puxty, A. G. (1979). Social science frameworks and accounting research. Discussion Paper No. 79.6, University of Sheffield, United Kingdom.

Puxty, A. G., Willmott, H. C., Cooper, D. J., \& Lowe, T. (1987). Modes of regulation in advanced capitalism: Locating accountancy in four countries. Accounting, Organizations and Society, 12(3), 273-291.

Ramanathan, K. V. (1976). Towards a theory of corporate social accounting. The Accounting Review, 51(3), 516-528.

Tomkins, C. (1982). The use of accounting information in a social services department and a police force: A comparison of two case studies. Discussion Paper, School of Management, University of Bath.

Vogel, D. (1978). Lobbying the corporation: Citizen challenges to business authority. New York, NY: Basic Books. 